NASA Technical Memorandum 106698

AIAA-94-3175

\title{
Cryogenic Gellant and Fuel Formulation for Metallized Gelled Propellants: \\ Hydrocarbons and Hydrogen \\ With Aluminum
}

Wing Wong, John Starkovich, and Scott Adams

TRW Space and Technology Division

Redondo Beach, California

Bryan Palaszewski

Lewis Research Center

Cleveland, Ohio

Prepared for the

30th Joint Propulsion Conference

cosponsored by AIAA, ASME, SAE, and ASEE

Indianapolis, Indiana, June 27-29, 1994

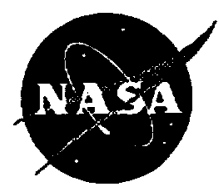

National Aeronautics and Space Administration

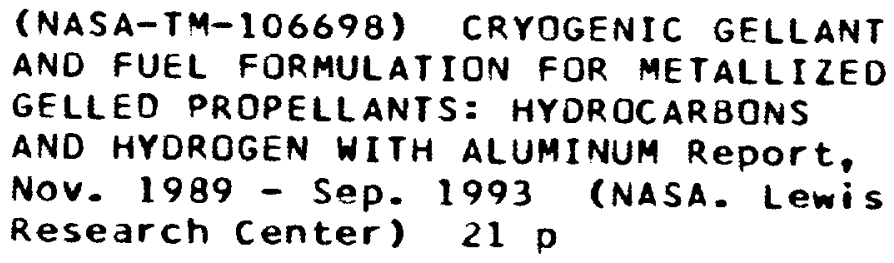

N95-10821

Unclas

$63 / 20$

0019873 

Cryogenic Gellant and Fuel Formulation for Metallized Gelled Propellants:

Hydrocarbons and Hydrogen with Aluminum

Drs. Wing Wong, John Starkovich, and Scott Adams

TRW Space and Technology Division

Redondo Beach, CA

Bryan Palaszewski

NASA Lewis Research Center

Cleveland, $\mathrm{OH}$

\begin{tabular}{|c|c|c|}
\hline Abstract & & Nomenclature \\
\hline $\begin{array}{l}\text { An experimental program to determine the } \\
\text { viability of nanoparticulate gellant materials for } \\
\text { gelled hydrocarbons and gelled liquid hydrogen } \\
\text { was conducted. The gellants included } \\
\text { alkoxides (BTMSE and BTMSH) and silica- } \\
\text { based materials. Hexane, ethane, propane and } \\
\text { hydrogen were gelled with the newly- } \\
\text { formulated materials and their rheological } \\
\text { properties were determined: shear stress versus } \\
\text { shear rate and their attendant viscosities. } \\
\text { Metallized hexane with aluminum particles was } \\
\text { also rheologically characterized. The propellant } \\
\text { and gellant formulations were selected for the } \\
\text { very high surface area and relatively-high } \\
\text { energy content of the gellants. These new } \\
\text { gellants can therefore improve rocket engine } \\
\text { specific impulse over that obtained with } \\
\text { traditional cryogenic-fuel gellant materials: } \\
\text { silicon dioxide, frozen methane, or frozen } \\
\text { ethane particles. Significant reductions in the } \\
\text { total mass of the gellant were enabled in the } \\
\text { fuels. In gelled liquid hydrogen, the total mass } \\
\text { of gellant was reduced from } 10-40 \text { wt \% of } \\
\text { frozen hydrocarbon particles to less than } 8 \text { wt } \\
\text { \% with the alkoxide. }\end{array}$ & $\begin{array}{l}\text { BTMSE } \\
\text { BTMSH } \\
\mathrm{CO}_{2} \\
\mathrm{H}_{2} / \mathrm{Al} \\
\mathrm{I}_{\text {sp }} \\
\mathrm{K} \\
\mathrm{MMH} / \mathrm{Al} \\
\mathrm{NASA} \\
\text { NBP } \\
\text { NFP } \\
\text { NTO } \\
\mathrm{n}_{\infty} \\
\mathrm{O}_{2} / \mathrm{H}_{2} \\
\mathrm{P} \\
\text { PZT } \\
\mathrm{Q} \\
\mathrm{RP}-1 / \mathrm{Al} \\
\text { SAD } \\
\text { TEOS } \\
\text { TEM }\end{array}$ & $\begin{array}{l}\text { Brunauer-Emmett-Teller surface } \\
\text { area measurement } \\
\text { Alkoxides with Ethyl } \\
\text { Hydrocarbons } \\
\text { Alkoxides with Hexyl } \\
\text { Hydrocarbons } \\
\text { Carbon Dioxide } \\
\text { Hydrogen/Aluminum } \\
\text { Specific Impulse (lb } \mathrm{b}_{\mathrm{f}} \mathrm{s} / \mathrm{lb} \text { ) } \\
\text { Temperature in Kelvin } \\
\text { Monomethyl Hydrazine } \\
\text { /Aluminum } \\
\text { National Aeronautics and Space } \\
\text { Administration } \\
\text { Normal Boiling Point } \\
\text { Normal Freezing Point } \\
\text { Nitrogen Tetroxide } \\
\text { Limiting Viscosity (Pa-s) } \\
\text { Oxygen/Hydrogen } \\
\text { Expulsion Pressure } \\
\text { Piezoelectric } \\
\text { Mass Flow Rate } \\
\text { Rocket Propellant-1/Aluminum } \\
\text { Selected Area Diffraction } \\
\text { Tetraethoxysilane } \\
\text { Transmission Electron } \\
\text { Microscopy }\end{array}$ \\
\hline
\end{tabular}




$\begin{array}{ll}\text { TRW } & \begin{array}{l}\text { Thompson, Ramo, and } \\ \text { Woolridge }\end{array} \\ \mathrm{t}_{\mathrm{y}} & \text { Yield Stress (Pa) } \\ \text { wt \% } & \text { Weight Percent }\end{array}$

\section{Introduction}

Liquid rocket propellant engines, including $\mathrm{O}_{2}, \mathrm{H}_{2}$ engines, have significantly contributed to many magnificent achievements in human and robotic space flight. 1 However, advanced propulsion systems that offer improved performance are required to make the next generation of launch vehicles and space transportation and exploration missions possible. Studies by the NASA-Lewis Research Center 2,3 have identified advanced gelled propellants such as $\mathrm{H}_{2} / \mathrm{Al}, \mathrm{RP}-1 / \mathrm{Al}$, and other gelled propellants as showing significant performance gains. Metallized propellants may have modestly higher specific impulses (Isp increases of 5 to $6 \mathrm{lb}_{\mathrm{r}}-\mathrm{s} / \mathrm{b}_{\mathrm{m}}$ for $\mathrm{O}_{2} / \mathrm{H}_{2} / \mathrm{Al}$ system, $60 \mathrm{wt} \% \mathrm{Al}$ in the $\mathrm{H}_{2} / \mathrm{Al}$ fuel) compared to nonmetallized hydrogen fuels. For proposed NASA Mars evolution and expedition missions, it has been estimated that metallized propellants can result in a 20 to $33 \%$ improvement in surface payload delivery capability. 2 More importantly for $\mathrm{O}_{2} / \mathrm{RP}-1 / \mathrm{Al}$ and NTO/MMH/Al propellants, adding metal can deliver considerably higher propellant density, depending on the application. Hence, both the tankage mass as well as the overall propulsion system dry mass can be substantially reduced. The propellant density increases and their attendant $I_{s p}$ changes with the aluminum additives allow a payload increase of 14 to 35 percent by replacing the Space Shuttle Solid Rocket Booster with a Liquid Rocket Booster using $\mathrm{O}_{2} / \mathrm{RP}-1 / \mathrm{Al}$ and NTO/MMH/Al, respectively. ${ }^{3}$

In metallized fuels, it is imperative that the dense metal particles are dispersed homogeneously throughout the fluid, and remain arrested in the liquid propellant during storage and transport. The distribution of particles is achieved by proper mixing, while the particle suspension requirement can be met by gelling the metallized fuel. Gelling also provides additional benefits including the reduction of sloshing, potential reduction of boil off or vaporization losses, better operational safety, and fuel storability. The gelation of $\mathrm{H}_{2}$ fuel was successfully demonstrated in earlier NASA studies. 4,5,6 More recently, gelation of metallized liquid propellants, such as Inhibited Red Fuming Nitric Acid/Monomethyl Hydrazine (IRFNA MMH), has also been demonstrated at ambient condition. ${ }^{7}$ However, the studies of cryogenic fuels employed high loadings of silica particles (10 to $40 \mathrm{wt} \%$ of the fuel) 8 to prevent the metal particles from settling. However, silica does not make the combustion process more energetic, making these type of gelled propellants impractical for propulsion applications. More efficient gellants that provide higher combustion energy are desirable.

The silica gellant materials employed in earlier studies were produced pyrogenically and have nominal surface areas and particle diameters of approximately $100 \mathrm{~m}^{2}$ and $15 \mathrm{~nm}$, respectively. The higher surface area translates into higher gelling efficiency, and therefore less gellant is used. These smaller dimension gellant particles may be prepared using sol-gel synthesis procedures and advanced processing methods. In particular, tailored organic polymers are attractive candidate gelling agents since these materials are efficient gelling agents for nonpolar liquids and they contribute energy to the combustion of the cryogenic gel propellants.

\section{Technical Description}

\section{Objectives}

The principal objective of this work was to explore the feasibility of developing a new class of gellant materials useful for formulating advanced cryogenic gel propellants. The goal was to demonstrate the synthesis and preparation of nanometer-dimension polymer gellant materials which are capable of efficiently gelling cryogenic liquid fuels and useful for preparing attractive metallized gel 
propellant formulations. A second objective was to provide a preliminary evaluation of the rheological properties of candidate gel formulations to determine whether they have attractive flow properties for propulsion applications

\section{Approach}

The technical approach included the development of advanced gellant materials through sol-gel syntheses and zero-surface tension processing techniques, including supercritical drying and freeze drying, thereby obtaining the desirable features, such as nanoparticulate size and positive combustion energy.

A second part of the program was the characterization of the rheology of gelled liquid propellants (neat and metallized) at room and cryogenic temperatures, thereby demonstrating the pertinent flow characteristics, and the stability of the gels and the particle dispersion. Early in the program, gelled liquid propellants included hexane, propane, and ethane served to simulate some of properties of gelled metallized hydrogen at reduced cost. One of the most important features was the metal loading in the gelled fuel. The measurement of the viscosity of gelled, metallized, liquid hydrogen was sought to demonstrate the gelling capability of the nanoparticulate gellants at extremely low temperatures.

The work performed under this project was exploratory in nature and principally directed at producing a new class of gellant materials useful for extremely low temperature service. The project was highly successful in meeting this aim and has confirmed the attractive gel formation properties of nanoparticulate materials for cryogenic fluids.

\section{Technical Discussion}

\section{Gellant Sol-Gel Synthesis}

Sol-gel material synthesis methods were selected for the preparation of candidate advanced gellant materials. Sol-gel processing technology has been extensively studied and used to prepare a wide variety of finemicrostructure film, foam and powder materials. ${ }^{9}$ The technology utilizes solutionbased polymer synthesis reactions and well established product drying/recovery methods for preparing multi-component materials with homogeneous molecules. The technology has several attractive features; it is readily scalable for producing large product volumes if eventually required, it utilizes commercially available precursors for starting materials, and it is uniquely capable of preparing combinational type materials like organoceramic polymers. This latter feature is particularly needed for preparing gellant materials with selectable chemical properties and affinities for fluids with widely differing polarities.

The candidate gellant materials were prepared from organic compound polymerization reactions carried out in alcohol solution. The starting compounds used in the synthesis reactions were boron and silicon esters of ethyl and methyl alcohol. These compounds are known as alkoxides and are commonly used reagents in sol-gel synthesis of various glass and ceramic composition materials. Alkoxides containing ethyl (BTMSE) or hexyl (BTMSH) hydrocarbons were also used for synthesis purposes where an organic group was desired in the final polymer gellant material. The polymerization reactions were initiated through acid-catalyzed hydrolysis of the alkoxide compound. Illustrative examples of the overall reactions involved in the synthesis of single and copolymer composition products are given in Equations 1, 2, and 3.

The hydrolysis and polymerization reactions proceed to form weakly-coherent, translucent alcogels in the reaction medium. Gel formation typically required anywhere from a few minutes to 24 hours depending on the catalyst, monomer concentration and temperature conditions employed. 


$$
\begin{aligned}
& \mathrm{m} \mathrm{B}\left(\mathrm{OCH}_{3}\right)_{3}+3 \mathrm{~m} \mathrm{H}_{2} \mathrm{O} \rightarrow \mathrm{m} \mathrm{H}_{3} \mathrm{BO}_{3}+3 \mathrm{~m} \mathrm{CH}_{3} \mathrm{OH} \\
& \text { Boric Acid Methanol } \\
& \mathrm{n} \mathrm{Si}\left(\mathrm{OC}_{2} \mathrm{H}_{5}\right)_{4}+4 \mathrm{n} \mathrm{H}_{2} \mathrm{O} \rightarrow \mathrm{n} \mathrm{Si}(\mathrm{OH})_{4}+4 \mathrm{n} \mathrm{C}_{2} \mathrm{H}_{5} \mathrm{OH} \\
& \text { Silanol Ethanol }
\end{aligned}
$$

Linear borosilicate polymer

$$
\mathrm{m} \mathrm{H}_{3} \mathrm{BO}_{3}+\mathrm{n} \mathrm{Si}(\mathrm{OH})_{4} \quad \rightarrow
$$

or

$$
[\mathrm{B} 2 \mathrm{O} 3]_{\mathrm{m} / 2}\left[\mathrm{SiO}_{2}\right]_{\mathbf{n}}
$$

Crosslinked borosilicate polymer

Product Drying and Recovery. The precursors react to form, coherent polymer alcogels from homogeneous solutions containing as low as 0.05 molar monomer. These polymer alcogels consist of delicate threedimensional structural networks that cannot be dried using conventional methods, such as vacuum bake and oven heating since these methods can lead to high surface tension forces at the solid-fluid interface and cause the networks to collapse. Two-zero surface tension drying techniques, freeze-drying and supercritical fluid processing, were used to recover products for this study. The freeze-dry process is depicted in Figure 1. It involves solvent freezing followed by evaporation of the frozen solvent at reduced pressure. A commercial unit having a processing capability of 5 liters was used in this study. Critical fluid processing involves the use of a fluid such as $\mathrm{CO}_{2}$ in a supercritical state. By raising the pressure and temperature above the critical point of the exchange fluid ( $304.2 \mathrm{~K}$ and 73 atm for $\mathrm{CO}_{2}$ ), it is possible to extract the solvent from the alcogel without encountering significant surface tension forces at the solidfluid interface. The apparatus used for supercritical processing is shown in Figure 2. Nanoparticulate gellant materials with large specific surface areas were successfully prepared using both methods.

Physical Characterization. The particle size and specific surface area of the polymer gellant materials prepared by freeze-drying and supercritical fluid processing were compared to select the drying technique for preparing nanogellant materials. Film samples of gellant powder were examined by transmission electron microscopy (TEM) and selected area diffraction (SAD) to determine the morphology and the crystalline nature. Both drying methods produced particles which have similar filamentous morphology and are highly amorphous as denoted in Figure 3. The filamentous particles appear to have large length-to-diameter aspect ratios (at least greater than 5 to 1). The particles produced by supercritical fluid processing appear to be somewhat smaller in size. This finding is supported by Brunauer-Emmett-Teller (BET) surface area measurements and supercritical fluid processing was consequently selected for production of nanogellant materials for further study.

Experimentally determined surface area (by BET), the elemental composition (by combustion analysis), and the heat of 
combustion (by calorimetry) of supercritical fluid processed gellant materials are summarized in Table I. The diameters for the individual, particles were calculated based on the assumptions that the individual particles are uniform spheres, with a true density of 2.2 $\mathrm{g} / \mathrm{cm}^{3}$. A true density is one where the total mass of gellant in the particles was fully compacted. The diameters of the uniform spheres were found to be 13,4 and $2 \mathrm{~nm}$, for BTMSH, silica, and BTMSE respectively. The BTMSE and BTMSH gellant polymers have low $\mathrm{H} / \mathrm{C}$ and $\mathrm{C} / \mathrm{Si}$ ratios, which suggest that the polymers are highly crosslinked. The BTMSH gellant exhibits slightly higher heat of combustion than the BTMSE gellant, which is attributed to BTMSH's longer aliphatic chain. The overall merits make the BTMSE gellant the preferred gellant material for cryogenic fuels.

Rheological Characterization of Neat and Metallized Hexane Gels

Hexane was chosen as the liquid hydrogen simulant for initial gel rheological property investigation since it is a non-polar liquid with a moderately low surface tension and easy to work with at ambient temperature.

Cone/Plate Viscometer. Figure 4 depicts the rheological properties of nanoparticulate hexane gels that were measured using a Brookfield cone-plate viscometer. Cone and plate instruments are preferred because they measure an absolute fluid viscosity .

Pseudoplastic Behavior. The viscosity of neat hexane gels containing different concentrations of nanoparticulate gellants was measured at different shear rates to determine their shear thinning properties. Gellant concentrations were varied from 5 to $20 \mathrm{~kg} / \mathrm{m}^{3}$ $(0.75$ to $3.05 \mathrm{wt} \%)$, which is equivalent to a gellant concentration range of 0.86 to $3.45 \mathrm{wt}$ $\%$ in liquid propane and ethane gels. Based on the relative fuel densities, this concentration corresponds to 7.0 to $28 \mathrm{wt} \%$ in liquid hydrogen gels. These nanoparticulate gelled propane and ethane exhibited considerable shear thinning, and the gel viscosity decreases by over two orders of magnitude upon being sheared at rates higher than $200 \mathrm{~s}^{-1}$, as seen in Figure 4. The shear-thinning properties of these gels are nearly identical for the BTMSEderived gel and silica gel (derived from tetraethoxysilane, TEOS) for fuels with the same gellant loading. These results suggest that the specific surface area and particle size of the gellant materials critically affect gelling efficiency.

Aluminum particle suspensions in hexane gelled with $5 \mathrm{~kg} / \mathrm{m}^{3}(0.76 \mathrm{wt} \%)$ of BTMSE were successfully prepared and observed to be stable for at least 4 months when kept in a specially fabricated plexiglas viewing container. Coarse (325 mesh, 44 microns) aluminum particles were selected for these tests and the loading level selected was 3.7 volume $\%$ (13.8 wt \%) which corresponds (on a relative density basis) to a $60 \mathrm{wt} \%$ aluminum loaded hydrogen fuel gel. This result demonstrates that, even at a low gellant concentration, sufficient gel yield strength is attained and large grain additives may be stably dispersed.

The metal-loaded dispersions exhibit pseudoplastic behavior similar to that observed for the neat gels. Analysis of the effect of shear rate on viscosity and the effect of gellant concentration on gel yield stress demonstrates that both neat and metallized nanoparticulate gelled fluids behave as "power-law" fluids. With this fluid model, the viscosities and the corresponding shear rates can be correlated by a power curve. This behavior is illustrated in the viscosity-shear rate data and it is shown in Figure 5. These gelled propellant systems were prepared using only $7.5 \mathrm{~kg} / \mathrm{m}^{3}$ (or $1.1 \mathrm{wt}$ $\%$ gellant) and are loaded with $13.8 \mathrm{wt} \%$ aluminum. Viscosities for these gels also fell within the target viscosity profiles set by NASA-Lewis for gelled propellants. The pseudoplastic index decreases from 0.40 to 0.02 upon the addition of aluminum particles.

\section{Yield Stress}

It is apparent from Figure 5 that both neat and metallized nanoparticulate gels behave like a viscous fluid at very low shear rates. The yield 
stress, $t_{y}$, a relative measure of gel strength, can be determined by extrapolating to zero shear rate. The yield stresses for a series of gels are plotted as a function of the gellant concentration in Figure 6. The inset log-log plot shows that yield stress may be correlated with a simple equation:

$t_{y}=t_{0}\left(C-C_{m}\right)^{a}$

where $t_{0}$ is a prefactor, $C$ is the gellant concentration, $a$ is an empirical constant, and $\mathrm{C}_{\mathrm{m}}$ is the minimum gellant concentration necessary to form a coherent gel structure. The fitted values for $a, C_{m}$, and $t_{0}$ are 3.06, 0.7 $\mathrm{kg} / \mathrm{m}^{3}$, and 2.6 , respectively. Such equations are indicative of percolating fractal structures. ${ }^{11}$

\section{Rheological Characterization of Neat and Metallized Cryogenic Gels}

The gelation properties of the nanoparticulate gellant at cryogenic temperatures were demonstrated with propane, ethane and methane. The normal boiling points of these cryogenic propellants are $230.1 \mathrm{~K}, 184.7 \mathrm{~K}$, and $111.6 \mathrm{~K}$, respectively, and are shown in Table II.

Liquefaction Apparatus and Cryoviscometer. The liquefaction apparatus used in gelation demonstration and rheological testing employed a copper condenser chilled with liquid nitrogen. This equipment was successfully used to condense liquid ethane and propane. However, attempts to condense the liquid methane were beset with recurrent plugging of the condenser/delivery tube since methane has a much narrower liquid temperature range $(21 \mathrm{~K})$ than other hydrocarbon fuels (81 K for ethane and $144 \mathrm{~K}$ for propane). Efforts were therefore concentrated on the demonstration of propane and ethane gels with BTMSE.

Cryogenic gels were successfully prepared in an apparatus in which the condensed liquid fuel is mixed with gellant materials in an open-cup, vacuum insulated, glass dewar and agitated with an ultrasonic probe. A Searle viscometer was modified to determine the cryo-rheological properties of the cryogenic fuel gels. The measuring element consists of two coaxial cylinders. Cryogenic fuel was placed in the gap between the outer (stationary) and the inner (rotating) cylinders. The viscometer is vacuum insulated to maintain thermal isolation. The measuring element is connected to the torque sensing element of a Haake Rotoviscometer through a ferrofluidics feedthrough .

\section{Cryogenic Gel Demonstration:}

Pseudoplastic Behavior. Neat propane gel was prepared using the gel preparation system and $7.5 \mathrm{~kg} / \mathrm{m}^{3}$ (or 1.3 wt \%) BTMSE gellant. The rheological properties of the propane and ethane gels, containing $7.5 \mathrm{~kg} / \mathrm{m}^{3}$ BTMSE gellant, were measured using the cryoviscometer. The shear stress versus shear rate profiles are given in Figure 7. The flow behavior of the gels may be described by a Casson model12 :

$$
\begin{aligned}
& t^{1 / 2}-t_{y} 1 / 2=\left(n_{\infty} \quad[\text { gamma dot] })^{1 / 2}\right. \\
& \text { gamma dot }=r(d \Omega / d r) \\
& t=T /\left(2 \pi r^{2} L\right)
\end{aligned}
$$

where $\mathrm{T}=$ torque on the cylinder, $\mathrm{L}$ is the length of the cylinder immersed in the gelled liquid, $\mathrm{r}$ is the radius in the cylindrical gap of the viscometer, $\Omega$ is the rotation rate of the cylinder, $t_{y}$ is the yield stress of the gel and $n_{\infty}$ is the limiting viscosity at very high shear rates. The values of $t_{y}$ and $n_{\infty}$ are $6.8 \mathrm{~Pa}$ and $6.4 \mathrm{mPa}$ $s$ for ethane gel and $1.7 \mathrm{~Pa}$ and $6.4 \mathrm{mPa}-\mathrm{s}$ for propane gel. These results indicate that these two gels have similar limiting viscosity at high shear rates, but the ethane gel has a slightly higher yield stress.

The viscosity properties of the neat gels in Figure 8 can be correlated using the power-law expression. A regression analysis showed that the pseudoplastic indexes are 0.22 for both ethane and propane gels. The ethane gel has a much thicker consistency compared to the propane gel as evident by the higher $\mathrm{k}$ value (0.47 $\mathrm{Pa}-\mathrm{s}^{0.22}$ versus $\left.0.22 \mathrm{~Pa}-\mathrm{s}^{0.22}\right)$. The high 
pseudoplastic index for these gel systems is very attractive for the design of low energy loss fluid transport systems and efficient atomization components.

\section{Cryo-Rheometer for Metallized Hydrogen Gels}

The existing literature on hydrogen viscosity measurements describe techniques that involve oscillating disks, torsional disks, and a variety of fine capillary tubes.12,13,14,15,16 It was anticipated that these approaches would not be applicable to the metallized hydrogen gels due to their non-Newtonian behavior. A direct measurement approach, using a cone-and-plate cryo-rheometer design, was therefore initially sought. Additional considerations for the design are the capability to condense liquid hydrogen, mix the metal additives and gellant materials with the liquid hydrogen, maintain temperature within a narrow liquid window of between 15 and $20 \mathrm{~K}$ during the rheological measurements, maintain an oxygen-depleted environment, and measure at low shear rate region for theological properties, such as yield point and pseudoplastic behavior.

The initial design was developed on the basis of the successful experience with cone/plate viscometers, and with preparing propane and ethane gels using an ultrasonic probe. The design involved the reconfiguration of the viscometer to submerse a heat exchange chamber containing the cone-plate measuring element into a liquid helium dewar. The condensed hydrogen would then be mixed with the metallic additives and nanoparticulate gellant inside the housing with the ultrasonic agitation of the in-situ piezoelectric (PZT) crystals. However, preliminary experimentation revealed that adequate ultrasonic mixing could not be reliably attained, and that mechanical stirring would be required. The design was hence modified to allow the gel ingredients be stirred in an external mixing chamber prior to transferring the hydrogen gel to the heat exchange chamber through an insulated delivery tube. The external mixer design was still considered to be too complicated to operate and its design could not ensure effective transfer of the gel due to the excessive thermal losses from the cryogenic (liquid helium) valves and long delivery tube. Due to these difficulties, the cone/plate viscometer design concepts were eventually abandoned.

\section{Canillary Flow Viscometer Design.} The final design selected was a capillary flow viscometer which is typically used to measure flow behavior of fluids in the high shear rate region. The key elements consist of two internal mixing cups of known volume connected with a transfer tube of predetermined inner diameter $(0.001 \mathrm{~m})$ and length $(1 \mathrm{~m})$. Each mixing cup is equipped with silicon diodes and heaters for temperature sensing and control. They are housed in a heat exchange chamber which is submerged in liquid helium inside a magnetic dewar. The interior of the heat exchange chamber is either filled with helium gas for thermal exchange between mixing cups and dewar, or in a vacuum to provide thermal isolation of the mixing cups. Hydrogen gas is condensed in the temperaturecontrolled buffers which function as liquid hydrogen reservoirs. The liquid hydrogen is mixed with metallic additives and nanoparticulate gellant in the mixing cups equipped with long-shaft stirrers and powered by twin external motors. An in-situ liquid level probe, which consists of a string of seriesconnected carbon resistors, is used to determine the quantity of hydrogen gel inside each mixing cup.

The key measurement is the time required to expel a known quantity of gel from one mixing cup to another. The gel expulsion is achieved through releasing helium gas into one of the two the mixing cups to establish a constant pressure gradient between the two mixing cups. These measurements provide the flow rate versus expulsion pressure (Q vs. P) profile for a given gel. The viscosity for Newtonian fluids can be determined using the HagenPoiseuille equation:

$\mathrm{n}=\pi \Delta \mathrm{PRc} 4 /(8 \mathrm{QL})$ 
and for power-law fluids:

$$
\begin{aligned}
& \mathrm{t}=\Delta \mathrm{P} \mathrm{R}_{\mathrm{c}} /(2 \mathrm{~L})=K(\text { gamma-dot }) \mathrm{n} \\
& \mathrm{n}=\mathrm{K}(\text { gamma-dot })^{\mathrm{n}-1}
\end{aligned}
$$

where $R c$ and $L$ refer to the inner radius and the length of the delivery tube, respectively.

Demonstration Test. A check-out run of the cryo-rheometer was conducted with liquid neon (normal boiling point [NBP] of $27.1 \mathrm{~K}$ ) and demonstrated that the system can safely be operated at liquid hydrogen temperatures.

This equipment was subsequently used to determine the viscosity of gelled hydrogen. In this experiment, nanoparticlulates derived from BTMSE (7 wt \%) were charged into the mixers, followed by liquid hydrogen. After thermal and chemical equilibria were attained (as evidenced by the temperatures becoming constant and by and zero pressure/gradient across the two mixers), helium gas was introduced into the first mixer, thereby creating a positive pressure of $1,000 \mathrm{~Pa}$ which expelled the hydrogen gel into the second mixer. By monitoring the liquid level probe inside the first mixer, the amounts of hydrogen gel transferred was determined, where each incremental voltage increase corresponds to a rise in resistance of the level probe which reflects a drop in liquid level between the two sequential carbon resistors.

It was found that approximately $48 \mathrm{~mL}$ were transferred in 120 seconds. Assuming Newtonian behavior, this transfer rate amounts to a viscosity of $0.064 \mathrm{mPa}-\mathrm{s}$ at a shear rate of $4,000 \mathrm{~s}^{-1}$. This is about 5 times higher than the viscosity of liquid hydrogen $(0.013 \mathrm{~Pa}-s)$ reported in the literature and demonstrates the thickening effect. These viscosities are shown in Table II. These shear rates and higher viscosities are not representative of those in a full-scale propulsion application, but they show a trend that implies that the gelled hydrogen will likely have a minimal viscosity difference from the ungelled hydrogen fuel under high velocity flow conditions.

\section{Concluding Remarks}

Advanced gellant materials were synthesized by means of the sol-gel methodology using organometallic compounds. The primary goal of this work was to explore the feasibility of a new class of nano-size (10-9 $\mathrm{m}$ ) materials for the effective gelation of metallized cryogenic fuels including suspended aluminum particles in liquid hydrogen. Two gellant materials were formulated specifically to provide a positive energy output upon combustion. The newlyformulated alkoxide gellants can provide 3.1 to $5.5 \mathrm{kcal} / \mathrm{g}$. Zero-surface tension drying techniques, such as freeze-drying and supercritical fluid drying, were employed to process the polymer products into large specific surface area, nano-size, particulates which serve as effective gellants. Polymer gellants produced by supercritical fluid process exhibit specific surface areas in the range of 600 to $1,000 \mathrm{~m}^{2} / \mathrm{g}$ and possess average particle diameters of 2 to $4 \mathrm{~nm}$. On the basis of its overall energy and high surface area merits, BTMSE and BTMSH polymer gellant materials was selected for rheological studies.

The gelling efficiency of polymer-derived nanoparticulates was successfully demonstrated using various neat and metallized propellant simulants including hexane, propane and ethane. Stable metallized hexane gels were prepared with as little as $5 \mathrm{~kg} / \mathrm{m}^{3}(0.75 \mathrm{wt} \%)$ nanoparticulate concentration, which would correspond to a $7.0 \mathrm{wt} \%$ gellant loading for hydrogen. This equates to a sixfold reduction in gellant concentration over the best gelling agents demonstrated in the 1960 's for gelling liquid hydrogen. The rheology of hexane gels in the low (less than $250 \mathrm{~s}^{-1}$ ) shear rate range was characterized with a Brookfield cone-plate viscometer. Both neat and metallized gels act as "power-law" fluids and exhibit pseudoplastic behavior, a behavior that is desirable for the storage and transportation of gelled propellants. 
Upon the addition of $13.8 \mathrm{wt} \%$ aluminum particles, these gels thickened and exhibited increased viscosity and the predicted pseudoplastic behavior. The yield strength of the $0.75 \mathrm{wt} \%$ polymer gellant in hexane was sufficient to prepare stable aluminum suspensions of interest to this project.

Cryogenic gels with $7.5 \mathrm{~kg} / \mathrm{m}^{3}$ (1.3 wt \%) of polymer-derived particulates in propane (230Kelvin, NBP) and ethane (185 K, NBP) were successfully prepared using a specially designed liquefaction and ultrasonic-dispersion system. The rheological properties in the low shear rate range were characterized using a modified Searle cryo-viscometer. These gelled cryogens also exhibit "power-law" fluid and pseudoplastic behavior. Their flow behavior can be described by a Casson fluid model. The ethane gels have a thicker consistency $\left(0.47 \mathrm{~Pa}^{-}\right.$ $\mathrm{s}^{0.22}$ vs. $0.22 \mathrm{~Pa}-\mathrm{s}^{0.22}$ ) and a higher relative yield strength (6.8 vs. 1.7$)$ than the propane gels.

In order to evaluate the gelling efficiency of polymer-derived nanoparticulates for extremely low temperature service, a 15-K capillary-flow viscometer was designed and assembled with a capability to mix pre-loaded metal particle additives and gellant with condensed hydrogen in-situ. A demonstration run was conducted with liquid hydrogen gel whose polymer gellant mass was $7 \mathrm{wt} \%$. This hydrogen gel exhibited a viscosity of $0.064 \mathrm{~Pa}-\mathrm{s}$ at a moderate shear rate of $4,000 \mathrm{~s}^{-1}$. This is approximately only about 5 times higher than that for liquid hydrogen alone. These shear rates and higher viscosities are not representative of those in a full-scale propulsion application, but they show a trend that implies that the gelled hydrogen will likely have a minimal viscosity difference from the ungelled hydrogen fuel under high velocity flow conditions.

These results successfully demonstrated the effectiveness of polymer-derived gellants for cryogenic propellants, and verified the general approach of using nanoparticulates to gel cryogenic fluids. Additional studies to characterize the rheology of neat and metallized hydrogen gels have also been conducted. The objective of any future gellant optimization would be to produce a gellant material that is efficient for gelling liquid hydrogen at concentrations less than 2 to $3 \mathrm{wt} \%$. At these concentration levels gellant material will have a much-reduced thermodynamic and engine system performance penalty over the currentlyrequired 7 to $8 \mathrm{wt} \%$ gellant level.

\section{Acknowledgements}

This paper describes work conducted by TRW Space and Technology Division under Contract NAS3-25793 during the period of November 1989 to September 1993. The project was managed by Drs. John A. Starkovich and Wing C. Wong of TRW. Major contributors included the following:

Dr. William Davison for gellant synthesis, Hareesh Thridandam for the rheological measurements and data analysis, William Burt for the cryo-rheometer design, Hsiao-Hu Peng for the cryo-rheometer fabrication and demonstration, Dr. Scott Adams for hydrogen gel rheology. Administrative review was conducted by Myrrl J. Santy, Manager of TRW's Advanced Materials and Products Department and NASA project management was provided by Bryan A. Palaszewski.

\section{References}

1) R. Wiswell and M. Huggins, "Launch Vehicle and Upper Stage Liquid Propulsion at the Astronautics Laboratory (AFSC) - A History Summary", AIAA 90-1839

B. A. Palaszewski, "Metallized Propellants for the Human Exploration of Mars", Case for Mars IV Conference, Boulder, CO, June 4-8, 1990

3) B. A. Palaszewski and R. Powell, "Launch Vehicle Performance Using Metallized Propellants", AIAA 902050, June 1991. 
4) NASA K-11-67-1 "A Study of Hydrogen Slush and/or Hydrogen Gel Utilization - Vol. I", 1968

5) NASA K-11-67-1 "A Study of Hydrogen Slush and/or Hydrogen Gel Utilization -Vol. II", 1968

6) G. Giola, W. Chew, D. Ryder, "Propulsion Systems Hazards Evaluation and Liquid/Gel Propulsion Component Development Program", Volume IV - Executive Summary, TRW, Inc., Final Report, Contract Number DAAH-01086-C-0114, Technical Report CR-RD-PR-90-1, December 1989.

7) N. Munjal, B. Gupta, and M. Varma, "Preparative and Mechanistic Studies on Unsymmetrical Dimethyl HydrazineRed Fuming Nitric Acid Liquid Propellant Gels," in Propellants, Explosives, and Pyrotechnics, 10, 4, $111,1985$.

8) E. Van der Wall, "Carbon Compounds/Liquid Hydrogen Fuels", Aerojet Liquid Rocket Company Final Report, Technical Report FR02-W396, October 1970, Contract SNP-1.

9) C. J. Brinker and G. W. Scherer, "SolGel Science," Academic Press, 1990.

10) R. B. Bird, R. C. Armstrong, and O. Hassager, "Dynamics of Polymeric Liquids - Vol. 1: Fluid Mechanics," John Wiley, New York, 1977

11) L. C. Klein, "Sol-gel Technology for Thin Films, Fibers, Preforms, Electronics, and Specialty Shapes," Noyes Publications, 1988.

12) C. C. Mills, "Rheology of Disperse Systems", Pergamon Press, New York, 1959

13) D. E. Diller, "Measurement of the Viscosity of Para-Hydrogen", J. of
Chem. Phys., 42 (6), 2089, 1965

14) H. E. Johns, "The Viscosity of Liquid Hydrogen, "Can. J. Res. 17A, 221, 1939

15) A. Van Itterbeek, H. Zink, and O. Van Paemel, "Viscosity Measurement in Liquified Gases", Cryogenics, 2, 210, 1962

16) N. S. Rudenko and V. G. Konareva, Zh. Fiz. Khim., 37, 2761 (1963)

17) M. Fatehi, M. Kaviany, R. Sonntag, B. Squires, and C. Kim, "Gelation of Liquid Nitrogen with Butane", Final Report, NASP Contractor Report, University of Michigan, Grant NAG3850, May 1990.

18) R. Barron, "Cryogenic Systems", McGraw-Hill, 1966. 


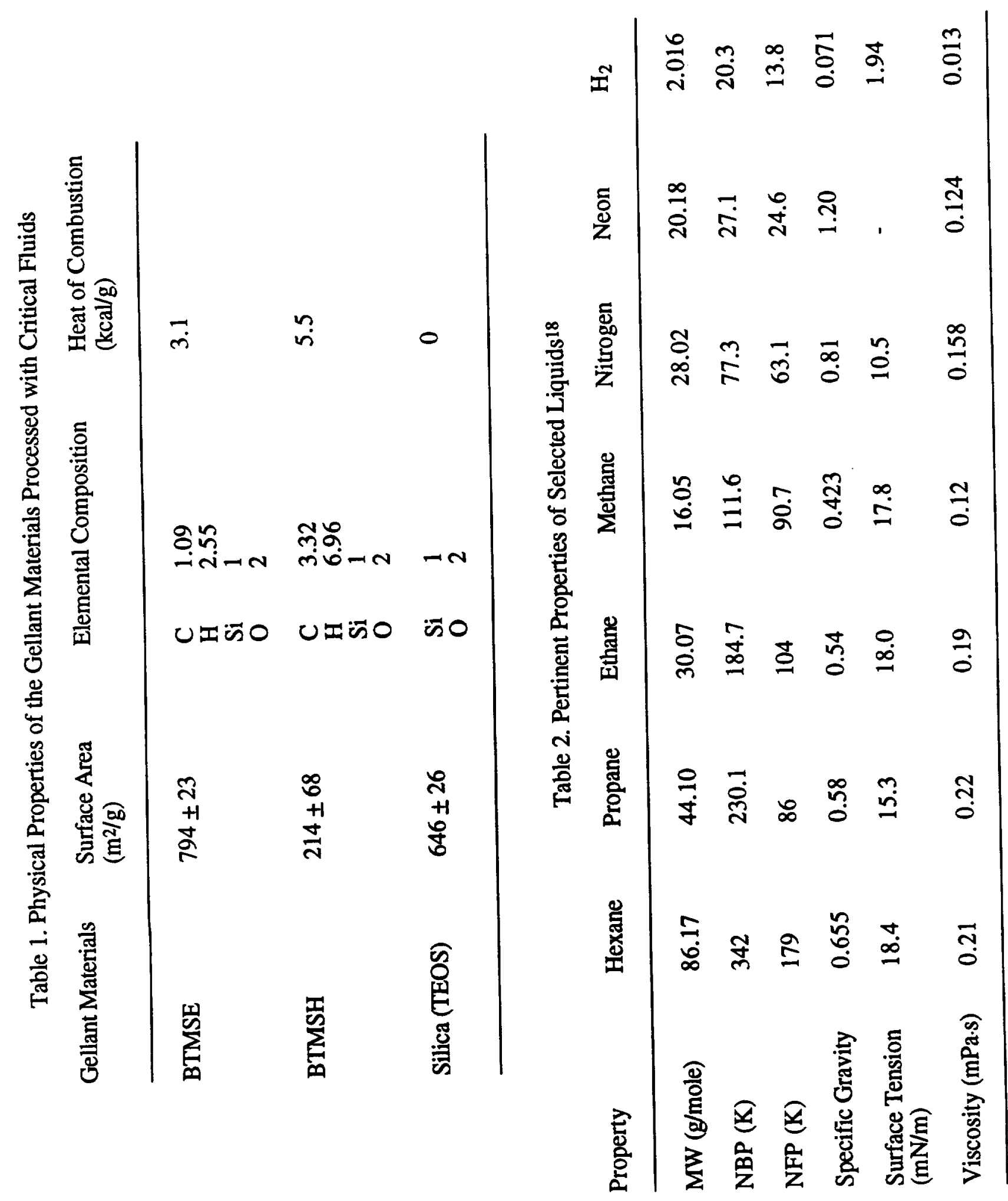




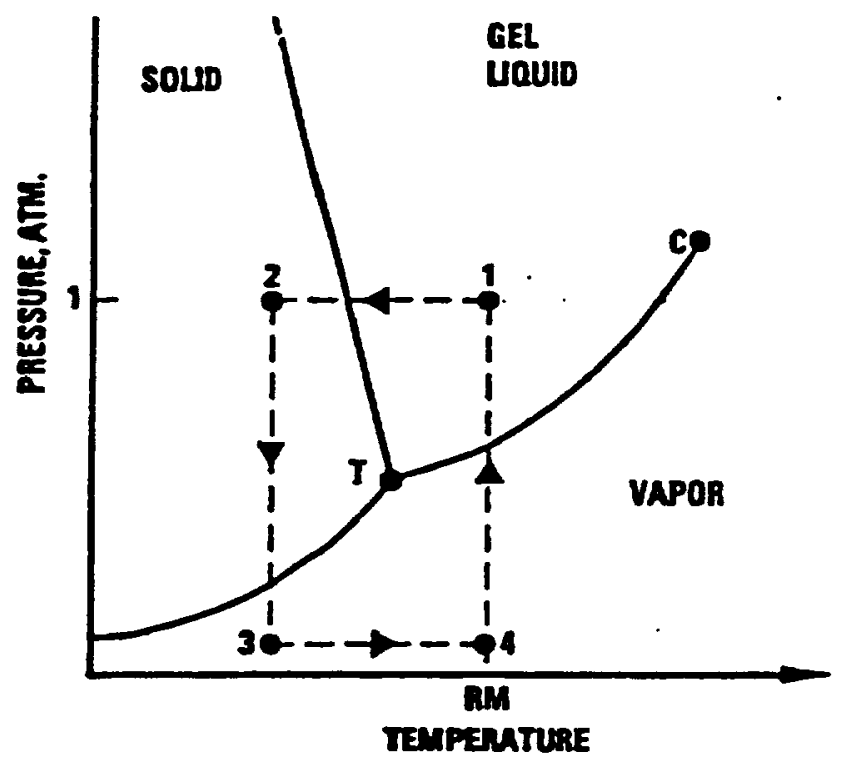

a. Process Design

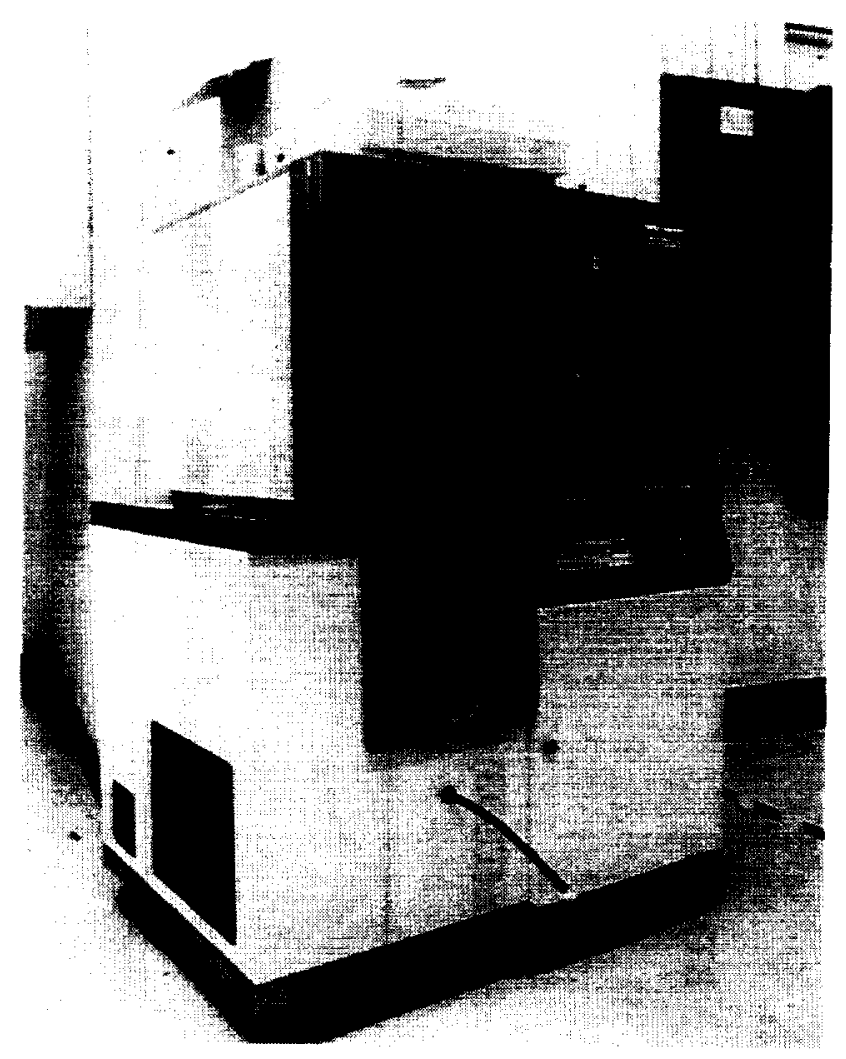

b. Commercial Unit

Figure 1. Nanogellant Preparation by Freeze Drying 


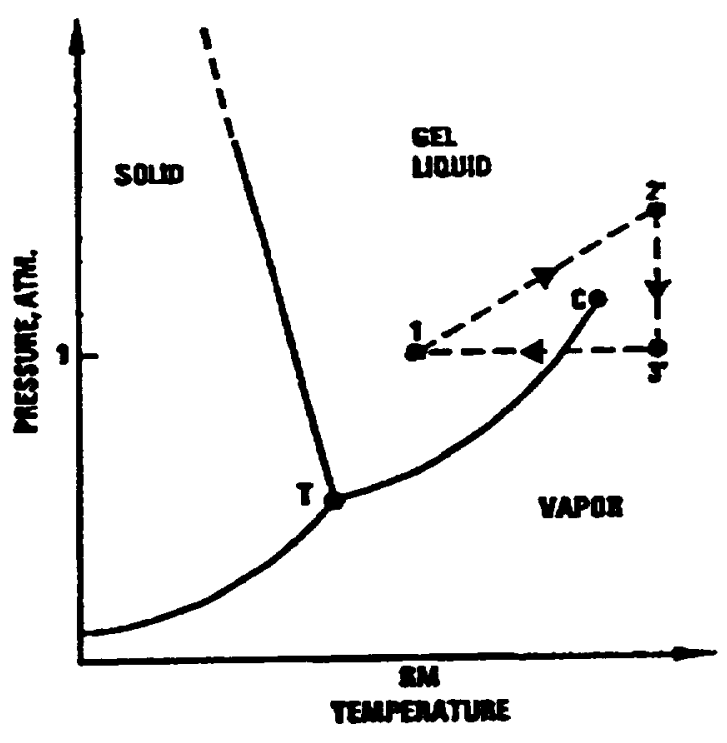

a. Process Design

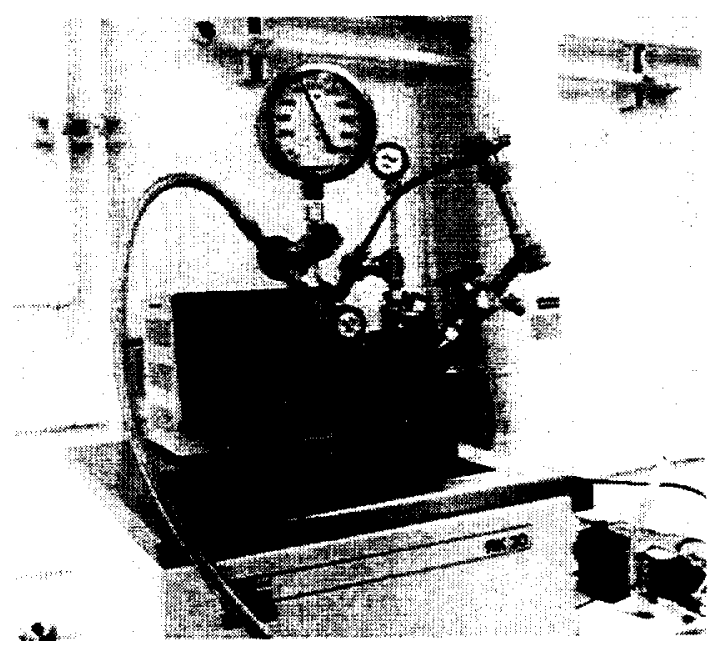

b. Research Unit

Figure 2. Nanogellant Preparation by Supercritical Fluid Processing 


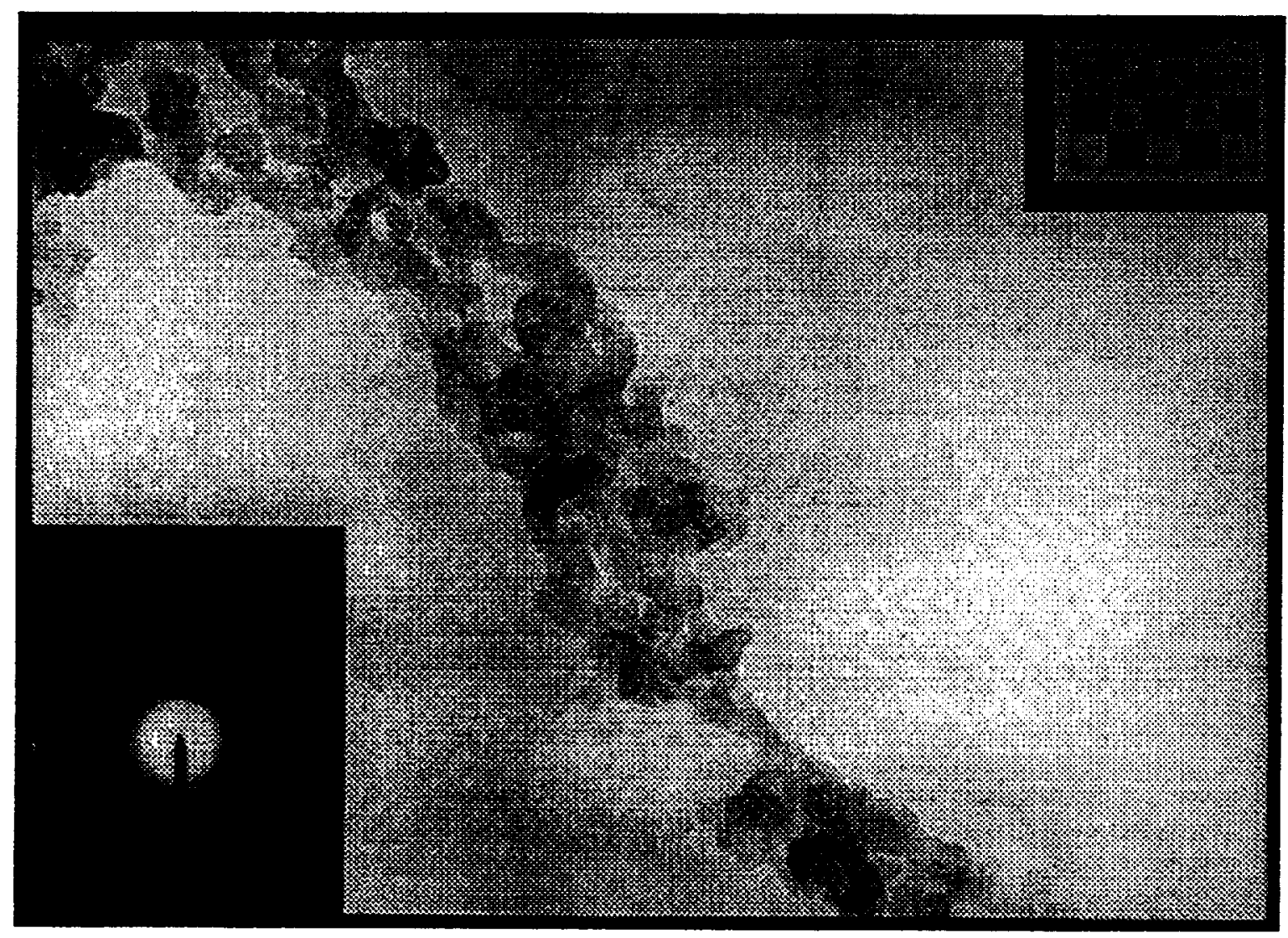

Figure 3. TEM Photomicrographs of Supercritical Fluid Processed BTMSE Gellant Particles (SAD Pattern shown in inserted picture) 


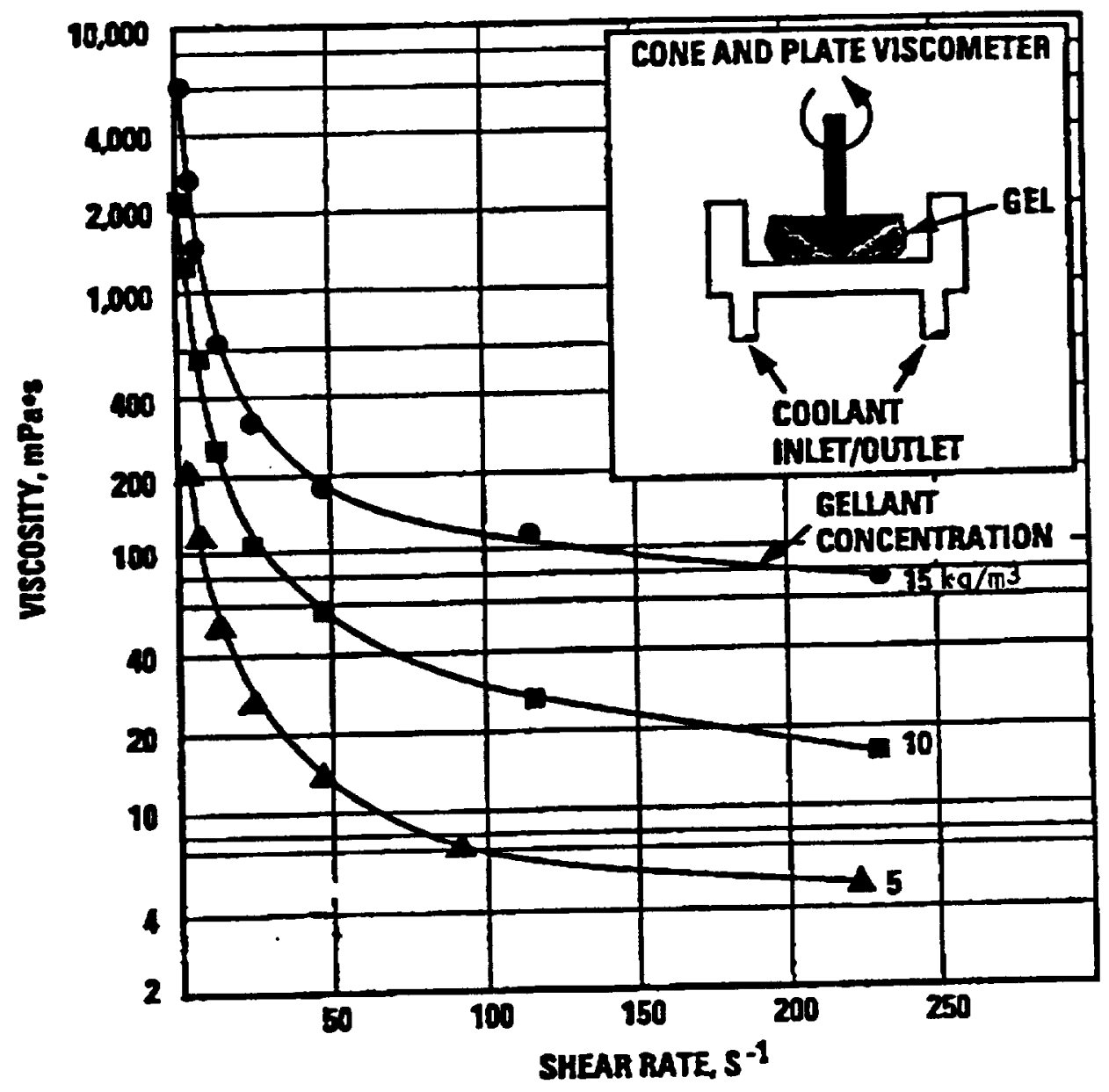

Figure 4. Pseudoplastic Behavior of BTMSE-Hexane Gelled Propellants 


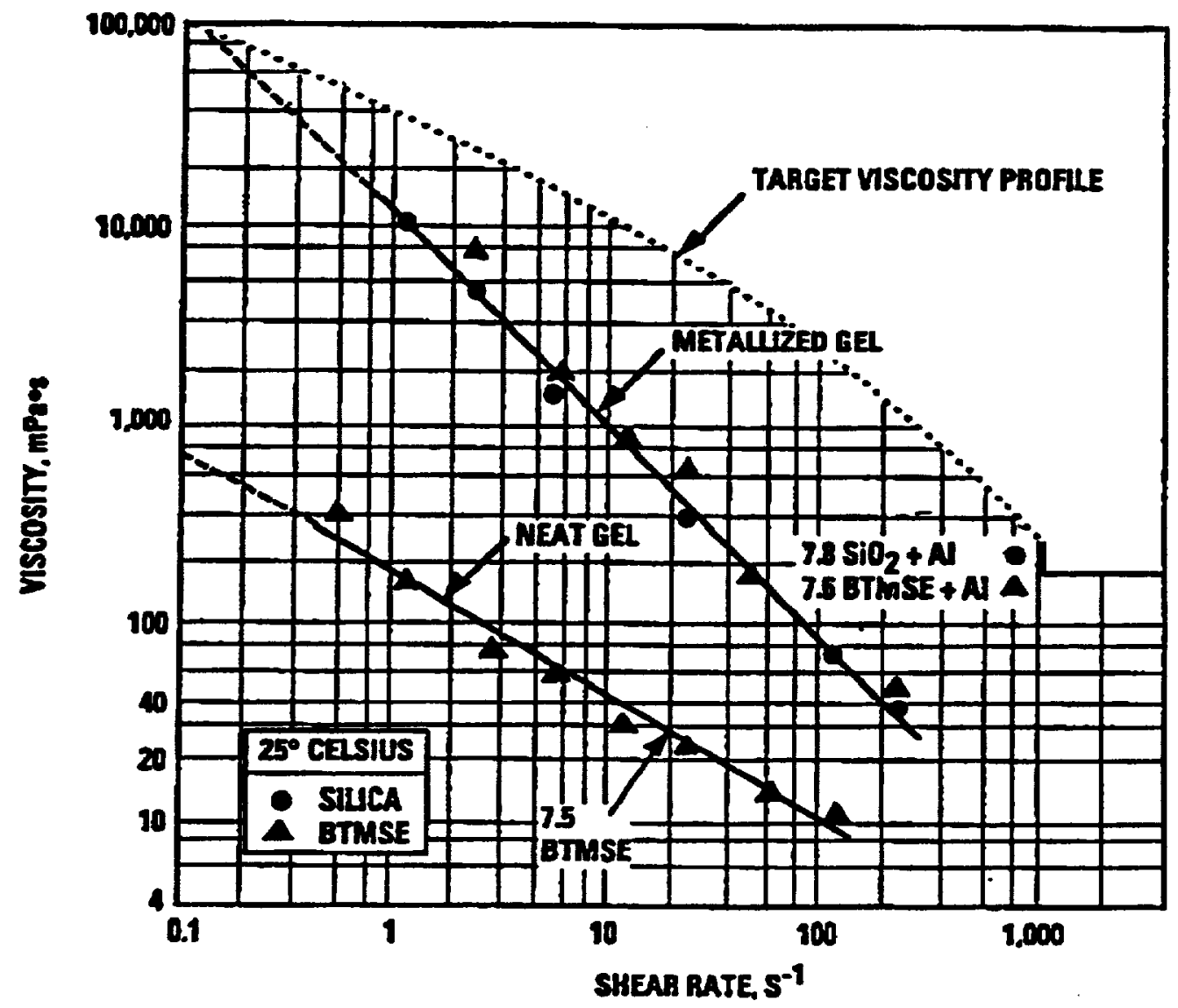

Figure 5. Power-Law Behavior of Nanoparticulate Gelled Hexane 


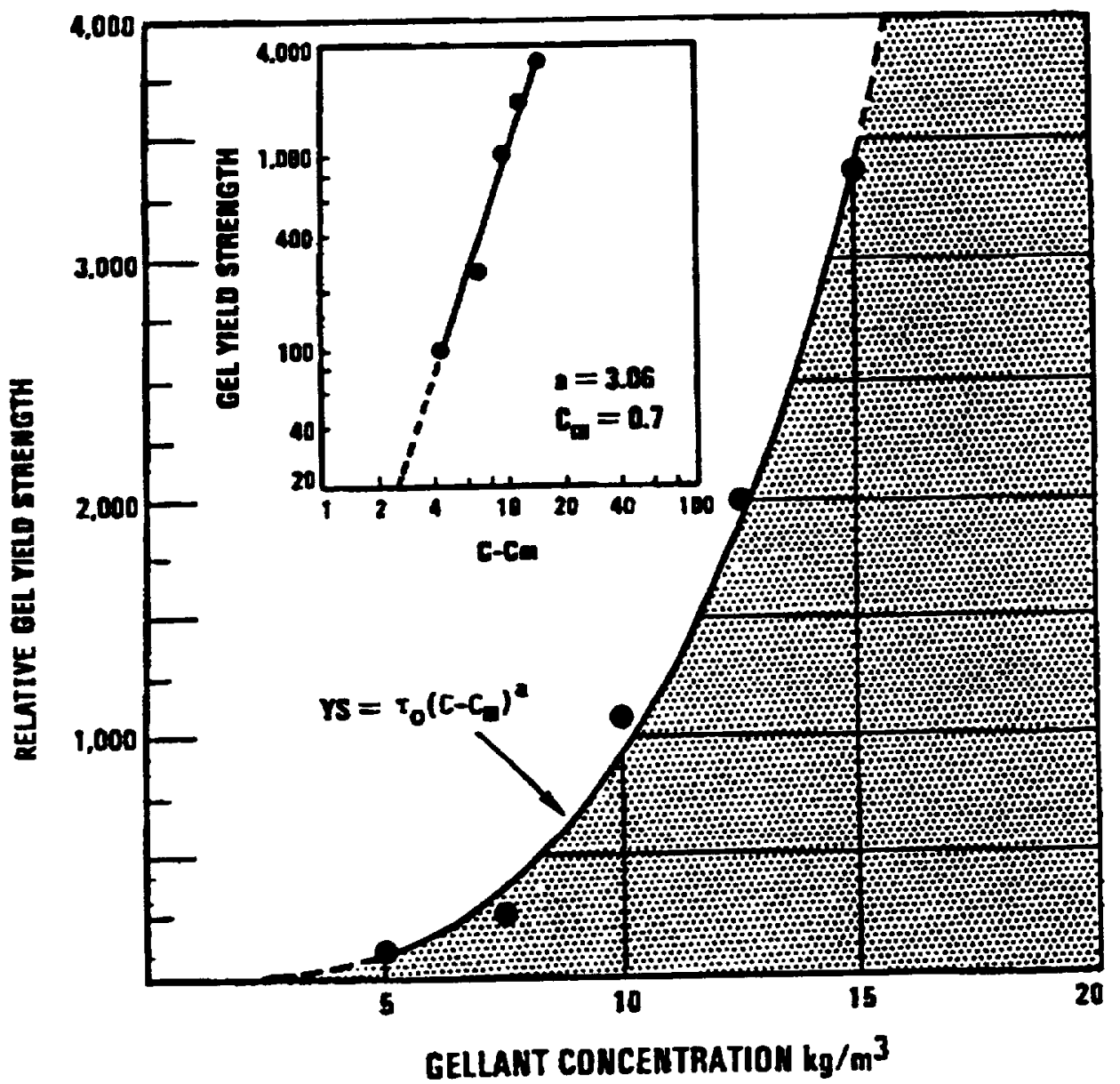

Figure 6. Yield Stress Dependence on Gellant Concentration (BTMSE-Hexane Gel at $298 \mathrm{~K}$ ) 


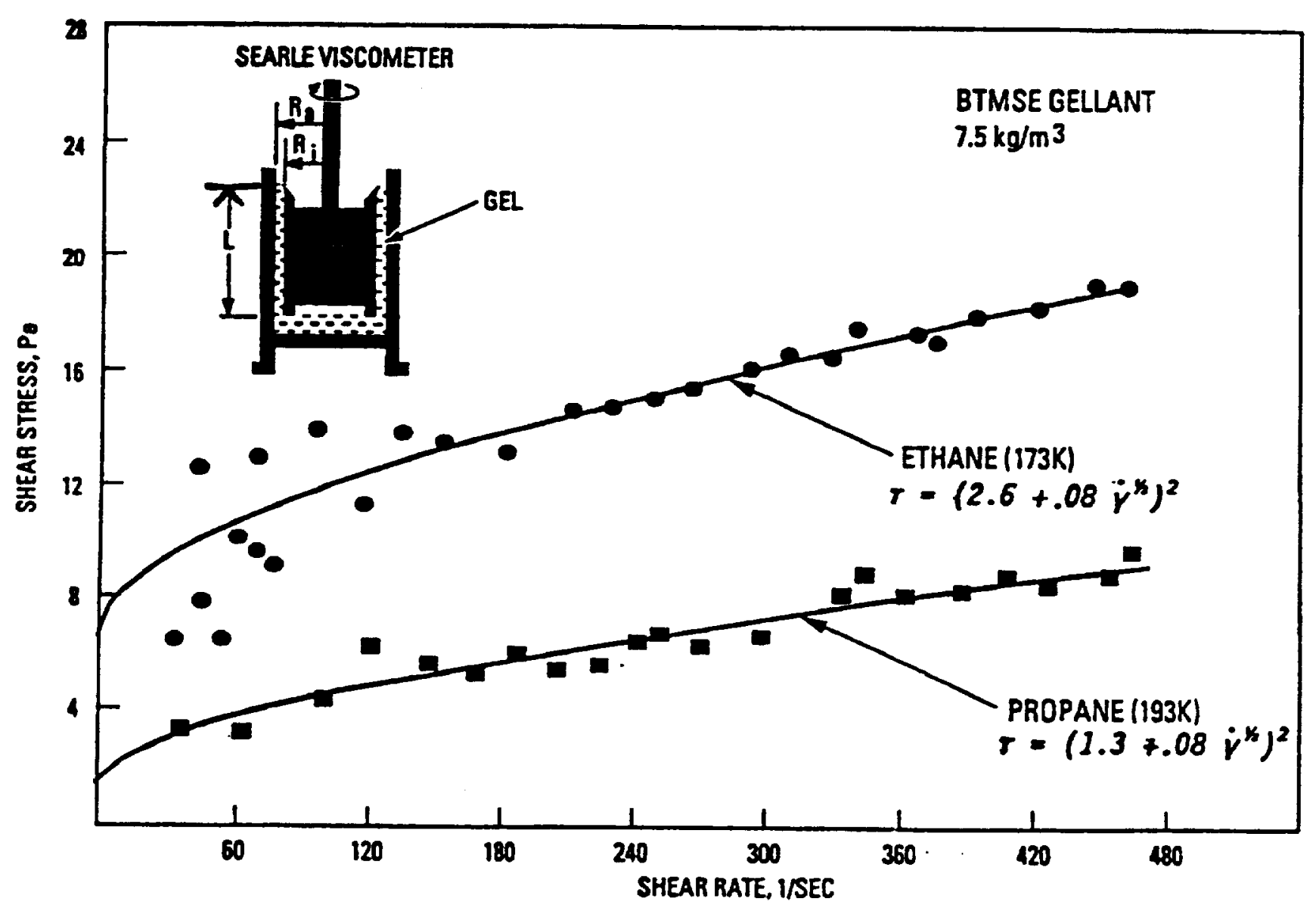

Figure 7. Rheological Properties of Nanoparticulate Gelled Cryogens (with Fitted Casson Fluid Models) 


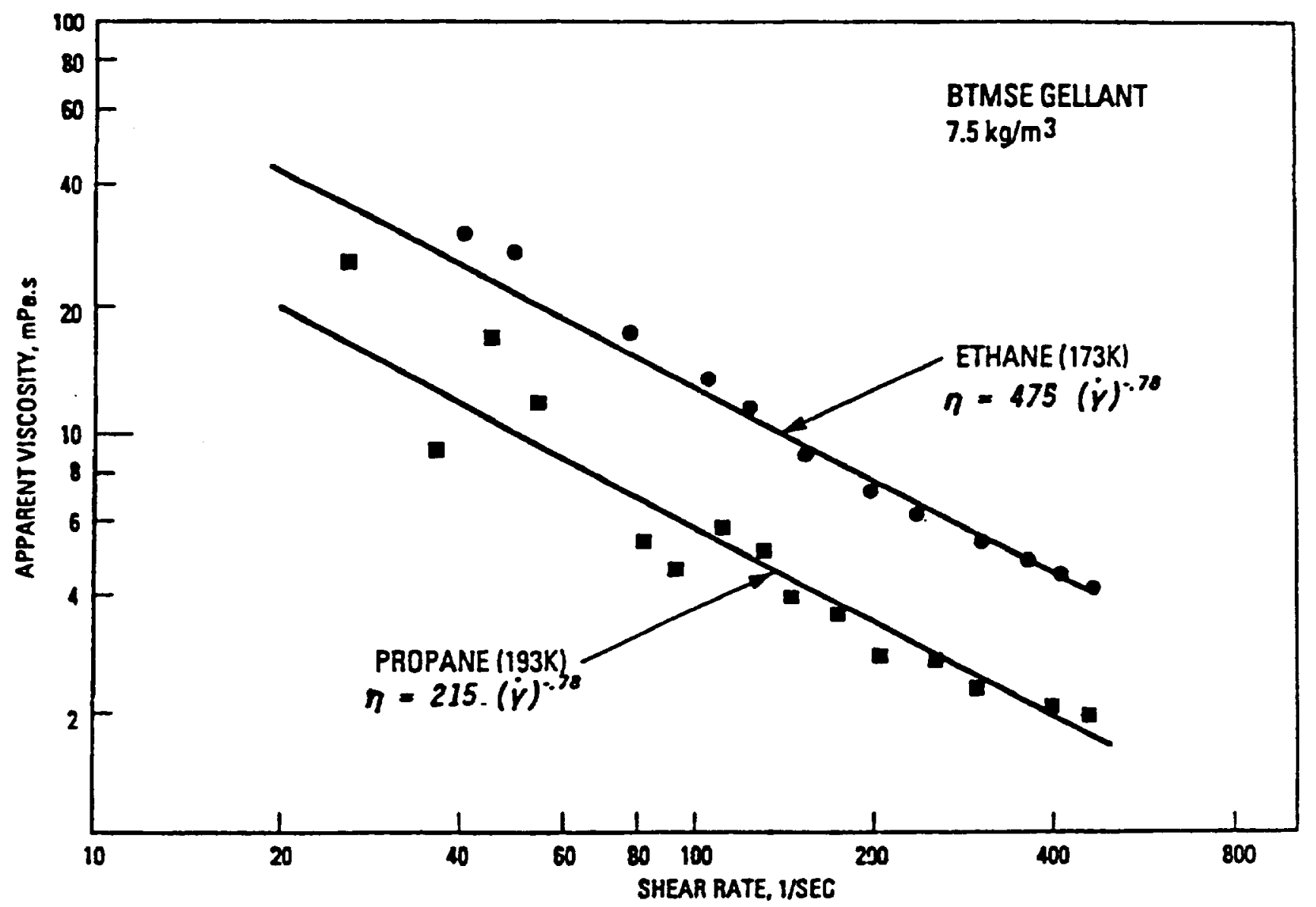

Figure 8. Pseudoplastic Behavior of Nanoparticulate Gelled Cryogens (with Fitted Power-Law Models) 
Public reporting burden for this collection of information is estimated to average 1 hour per response, including the time for reviewing instructions, searching existing data sources, gathering and maintaining the data needed, and completing and reviewing the collection of information. Send comments regarding this burden estimate or any other aspect of this
collection of information, including suggestions for reducing this burden, to Washington Headquarters Services, Directorate for Intormation Operations and Reports, 1215 Jefferson Davis Highway. Sulte 1204, Arlington, VA 22202-4302, and to the Office of Management and Budget, Paperwork Reduction Project (0704-0188), Washington, DC 20503.

\begin{tabular}{|l|c|r|}
\hline 1. AGENCY USE ONLY (Leave blank) & $\begin{array}{c}\text { 2. REPORT DATE } \\
\text { August } 1994\end{array}$ & $\begin{array}{r}\text { 3. REPORT TYPE AND DATES COVERED } \\
\text { Technical Memorandum }\end{array}$ \\
\hline
\end{tabular}

\section{TITLE AND SUBTITLE}

Cryogenic Gellant and Fuel Formulation for Metallized Gelled Propellants:

Hydrocarbons and Hydrogen With Aluminum

6. AUTHOR(S)

Wing Wong, John Starkovich, Scott Adams, and Bryan Palaszewski

\section{PERFORMING ORGANIZATION NAME(S) AND ADDRESS(ES)}

National Aeronautics and Space Administration

Lewis Research Center

Cleveland, Ohio 44135-3191

9. SPONSORING/MONITORING AGENCY NAME(S) AND ADDRESS(ES)

National Aeronautics and Space Administration

Washington, D.C. 20546-0001
5. FUNDING NUMBERS

WU-506-42-72
8. PERForming organization REPORT NUMBER

E-9059

11. SUPPLEMENTARY NOTES

Prepared for the 30th Joint Propulsion Conference cosponsored by AIAA, ASME, SAE, and ASEE, Indianapolis, Indiana, June 27-29, 1994. Wing Wong, John Starkovich, and Scott Adams, TRW Space and Technology Division, One Space Park, Redondo Beach, Califomia 90278 (work funded by NASA Contract NAS3-25793); Bryan Palaszewski, NASA Lewis Research Center. Responsible person, Bryan Palaszewski, organization code 5310, (216) $977-7493$.

12a. DISTRIBUTIONAVAILABILITY STATEMENT

Unclassified - Unlimited

Subject Categories 15, 16 and 20

10. SPONSORINGMONITORING AGENCY REPORT NUMBER

NASA TM-106698

AIAA-94-3175

13. ABSTRACT (Maximum 200 words)

An experimental program to determine the viability of nanoparticulate gellant materials for gelled hydrocarbons and gelled liquid hydrogen was conducted. The gellants included alkoxides (BTMSE and BTMSH) and silica-based materials. Hexane, ethane, propane and hydrogen were gelled with the newly-formulated materials and their rheological properties were determined: shear stress versus shear rate and their attendant viscosities. Metallized hexane with aluminum particles was also rheologically characterized. The propellant and gellant formulations were selected for the very high surface area and relatively-high energy content of the gellants. These new gellants can therefore improve rocket engine specific impulse over that obtained with traditional cryogenic-fuel gellant materials: silicon dioxide, frozen methane, or frozen ethane particles. Significant reductions in the total mass of the gellant were enabled in the fuels. In gelled liquid hydrogen, the total mass of gellant was reduced from $10-40 \mathrm{wt} \%$ of frozen hydrocarbon particles to less that $8 \mathrm{wt} \%$ with the alkoxide.

14. SUBJECT TERMS

15. NUMBER OF PAGES

Gelled propellants; Gellants; Metal propellants 21

16. PRICE CODE

$\mathrm{A} 03$

17. SECUAITY CLASSIFICATION
OF REPORT
Unclassified

18. SECURITY CLASSIFICATION OF THIS PAGE Unclassified

19. SECURITY CLASSIFICATION OF ABSTRACT Unclassified 